\title{
Integral quality indicators of waste concrete for reuse
}

\author{
Arkady M. Ayzenshtadt (iD, Victor E. Danilov (iD, Tatiana A. Drozdyuk* (iD, Maria A. Frolova (iD, \\ Georgiy A. Garamov i \\ Northern (Arctic) federal university named after M.V. Lomonosov, Arkhangelsk, Russia \\ * Corresponding author: e-mail: t.drozdyuk@narfu.ru
}

\begin{abstract}
Introduction. Waste concrete is one of the main heavy construction waste having good recycling prospects with regard to rational nature management related to reducing the consumption of natural resources. However, the widespread introduction of waste concrete is hindered on the one hand by the variety of compositions and structures of recycled scrap, and on the other hand by the lack of quantitative criteria to choose the most rational area of its use (a binder component, coarse and fine aggregate, finely dispersed filler, etc.). Materials and methods. Case studies of experimental powders obtained by mechanical grinding from the concrete scrap of internal wall panels and floor slabs (heavy concrete) and external wall panels (light concrete) of a five-storey residential panel house built in 1979 in the Obozersky village, Arkhangelsk region, demonstrated the possibility of choosing the optimal secondary use of waste concrete fractions featuring residual compressive strength. The indicators of residual strength, grindability and contraction of mineral powders were used as optimization criteria. Results and discussions. The applicability of the mathematical model for calculating the raw material grindability index is shown. A criterion for grinding equipment selection is proposed to obtain powders with an extended active surface. Conclusions. Powders obtained from the fraction of waste light concrete featuring low strength properties and grindability by mechanical grinding to a specific surface area comparable to that of Portland cement used and having a higher value of contraction can be rationally used as a composite binder component. Concrete scrap fractions featuring by higher grindability and strength properties are optimally suited for crushed aggregate preparation in the concrete composite production process.
\end{abstract}

KEY WORDS: concrete scrap, recycled concrete, grindability criterion, composite binder, mineral powder contraction.

ACKNOWLEDGMENTS: The research was carried out on the unique scientific equipment "Physical Chemistry of Surfaces of NanoDispersed Systems" with the financial support from Kolarctic project no. KO4068 "DeConcrete: Eco-efficient Arctic Technologies Cooperation".

FOR CITATION: Ayzenshtadt A.M., Danilov V.E., Drozdyuk T.A., Frolova M.A., Garamov G.A. Integral quality indicators of waste concrete for reuse. Nanotechnologies in Construction. 2021; 13(5): 276-281. https://doi.org/10.15828/2075-8545-2021-13-5-276-281.

\section{INTRODUCTION}

$\mathrm{B}$ esides addressing the problems related to heavy construction waste disposal, concrete scrap application in the production is also one of the promising areas of rational environmental management related to reducing the consumption of natural mineral resources. Thus, the use of secondary resources in this particular case has two important aspects: economic and environmental. However, the widespread introduction of used concrete is hindered on the one hand by the variety of compositions and structure of recycled scrap, and on the other hand by the lack of quantitative criteria to choose the most rational area of its use (binder component, coarse and fine aggregate, finely dispersed filler, etc.). Currently, there are various approaches to recommendations for recycled concrete application that are predominantly associated with its use as a coarse aggregate [1, 2]. However, using recycled concrete only as aggregates cannot be considered an optimal way to address the issue of recycling these materials. It is known that the concrete matrix contains unhydrated clinker particles that can form a new curing structure during grinding and subsequent hydration [3-6]. The unhydrated clinker part volume can reach

(c) Ayzenshtadt A.M., Danilov V.E., Drozdyuk T.A., Frolova M.A., Garamov G.A., 2021 
$20 \%[7,8]$. Thus, studies show that complete hydration is observed for $3 \mathrm{CaO} \cdot \mathrm{Al}_{2} \mathrm{O}_{3}\left(\mathrm{C}_{3} \mathrm{~A}\right)$ tricalcium aluminate by the $28^{\text {th }}$ day of concrete curing under normal humidity and temperature conditions. $3 \mathrm{CaO} \cdot \mathrm{SiO}_{2}\left(\mathrm{C}_{3} \mathrm{~S}\right)$ tricalcium silicate is hydrated by $70-75 \%$, and $2 \mathrm{CaO} \cdot \mathrm{SiO}_{2}$ $\left(\mathrm{C}_{2} \mathrm{~S}\right)$ bicalcium silicate is hydrated by $50-75 \%$. Thus, $\mathrm{C}_{3} \mathrm{~S}$ and $\mathrm{C}_{2} \mathrm{~S}$ particles remain unhydrated in the cement stone structure in concrete products. Therefore, concrete scrap from demolished buildings and structures, as a rule, contains clinker minerals capable of further hardening. Finely dispersed powder of recycled concrete with a significant residual content of unhydrated calcium silicates can be an active component in binding compositions. Based on the above, methods for evaluating the powder ability to form hydrosilicates of additional generation in a reaction with water can be used to predict the rational use of concrete scrap as a coarse (or fine) aggregate or component in binding compositions. Such methods include e.g. reducing the volume of the mixture (powder/water) due to hydration (contraction) [9-14]. This is due to the fact that the volume of cement stone newgrowths is less than the volume occupied by substances undergoing the hydration reaction (shrinkage develops intensively during the chemical reaction). Additional parameters that determine the rational use of waste concrete can be e.g. the grindability of samples and their residual compressive strength. The authors of the paper [15] proposed a quantitative grindability criterion - grindability index (GI) calculated by the expression:

$$
\mathrm{GI}=\left(S_{\text {spec } 2}-S_{\text {spec } 1}\right) / \Delta \tau \text {, }
$$

where $S_{\text {spec } 1}$ and $S_{\text {spec } 2}$ are specific surface areas of powders before and after mechanical grinding during the time $\Delta \tau$. In addition, the shape of particles obtained when grinding is no less important for obtaining an active (capable of chemical transformation) powder. Dispersed systems where particles feature by spherical symmetry form a less active surface than corner-shaped particles.

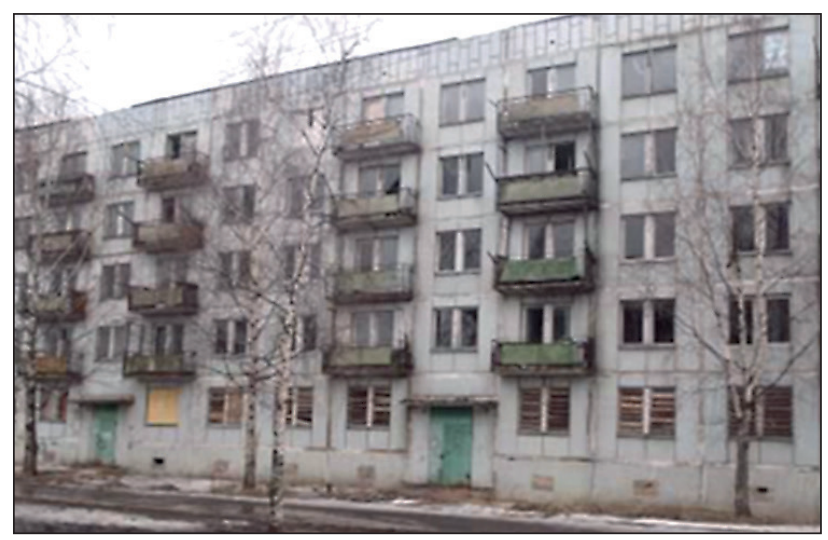

At the same time, it is necessary to take into account the fact of the relationship between the main dispersed properties of powders: particle size and specific surface area. So, if the particles have a near-spherical shape and exhibit the properties of elastic bodies, the ratio $[16,17]$ is valid:

$$
d=6 /\left(\rho_{\text {true }} \cdot S_{\text {spec }}\right),
$$

where $d$ is the average linear particle size; $\rho$ true is the true specific density of powder, $\mathrm{kg} / \mathrm{m}^{3}$. Thus, the greater the difference between the calculated value of $d$ according to expression (2) and the similar dimensional characteristic experimentally determined by modern methods (e.g. photon correlation spectroscopy), the higher the potential reactivity of the particle (or entire powder system). This criterion can be used when choosing the most optimal grinding machine.

The objectives of these studies are to: assess the contraction value of concrete scrap powders of different initial strength (light and heavy concrete) obtained from fragments of demolished buildings operated for more than 50 years; experimentally check the possibility of using highly dispersed powders as a component in composite binders (CB); reuse samples of waste concrete as an aggregate.

\section{MATERIALS AND METHODS}

Test samples of powders were made from concrete scrap of internal wall panels and floor slabs (heavy concrete, raw sample B1) and external wall panels (light concrete, raw sample B2) of a five-storey residential panel house built in 1979 in the Obozersky village, Arkhangelsk region (Fig. 1).The residual strength of samples was determined by the shock pulse method according to GOST 22690-2015 on the IPS-MG4 device.

Concrete test samples were split into pieces maximum 120x120x60 mm in size with subsequent reinforcement extraction. Then concrete fragments were crushed

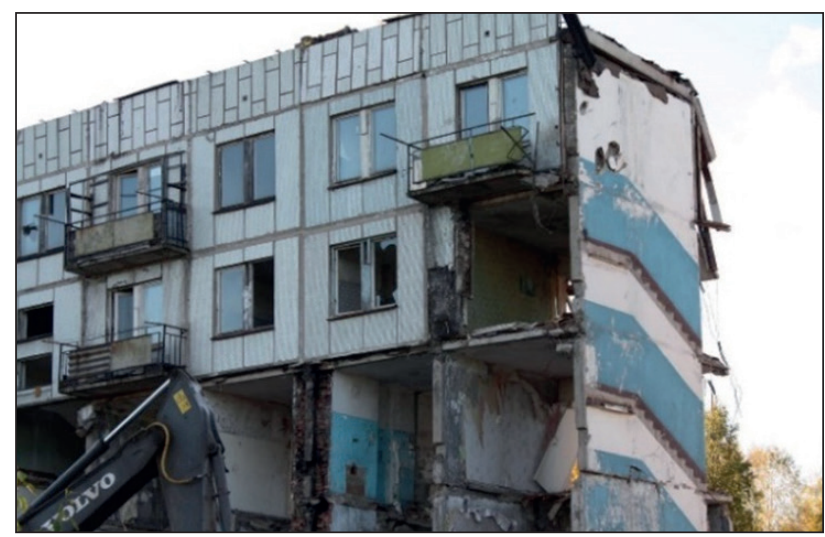

Fig. 1. Photo of a panel house built in 1979 
using the DShch 1-2 jaw crusher (Prommash, Russia). Screenings were divided into fractions on a standard set of sieves (GOST 3584-73) by a dry method. A fraction that passed through the Sieve No. 015 mesh was selected for further research. Thus, it can be assumed that particle size properties of $\mathrm{B} 1$ and $\mathrm{B} 2$ raw samples did not exceed $0.14 \mathrm{~mm}$. Before the final grinding, all the raw materials studied were brought to a constant mass in a drying cabinet at $60 \pm 5^{\circ} \mathrm{C}$ and subjected to the procedure of true density measurement according to the method specified in GOST 32763-2014 "Mineral Powder. The Method of Determining the True Density." The chemical composition of test samples was determined using the MetExpert X-ray fluorescence analyzer (Yuzhpolymetal-Holding, Moscow, Russia). The final mechanical grinding of raw materials was carried out to obtain a specific surface area comparable to that of Portland cement $\left(300 \div 500 \mathrm{~m}^{2} / \mathrm{kg}\right)$ by dry grinding in the Retsch PM100 planetary ball mill at a rotor speed of $420 \mathrm{rpm}$. The specific surface area of dispersed materials and dimensional properties of particles were measured by the Kozeny-Carman gas permeability methods at the PSKh-10a unit (Khodakov Devices, Russia).The activity of waste concrete powders obtained was determined by an accelerated method for 3 hours according to the cement paste contraction value using the Cement-Prognoz unit in accordance with MI 2486-98, MI 2487-98 measurement methods. Portland cement M500 was used for a comparative assessment of the activity of mineral powder systems. Physical and mechanical parameters (bending strength and compressive strength) of construction products $(40 \times 40 \times 160 \mathrm{~mm}$ cement-sand and

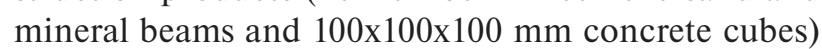
were determined in accordance with standard methods.

\section{RESULTS AND DISCUSSIONS}

Residual strength tests of experimental concrete samples showed that light (Sample B2) and heavy (Sample B1) concrete can be classified as Class B22,5 and Class B40, respectively. The average true specific density $(\rho)$ values of the samples studied were: $2253 \mathrm{~kg} / \mathrm{m}^{3}$ for Sample B2, and $2350 \mathrm{~kg} / \mathrm{m}^{3}$ for Samples B1. The elemental composition of Sample B1 and Sample B2 (in terms of oxides) differs significantly in the content of main components: $\mathrm{SiO}_{2}-36.68 \%$ and $16.73 \%, \mathrm{CaO}-51.39 \%$ and $76.63 \%, \mathrm{Fe}_{2} \mathrm{O}_{3}-11.18 \%$ and $5.89 \%$ for light (B2) and heavy (B1) concrete, respectively. The content of the rest elements can be considered as impurity one since their total amount does not exceed $1 \%$. Thus, the elemental composition analysis showed the absence of carcinogens (agents potentially dangerous for the human body) that could form in concrete during its long-term operation as a result of metasomatic processes. In further experiments, it was found that the 30-minute final mechanical grinding of concrete scrap samples obtained after the jaw crusher made it possible to obtain finely dispersed powders with a specific surface area and dimensional properties (average mass diameter) of particles comparable to those used in further experiments of Portland cement M500 (Sample PC500) (Table 1) with the true specific density of $2550 \mathrm{~kg} / \mathrm{m}^{3}$.

The results obtained (Table 1) show that concrete scrap with a higher residual strength features by increased grindability compared to a part of test samples having a reduced residual compressive strength corresponding to Class B22,5.

In order to determine the GI digital value according to equation (1), we used the values of corresponding powders obtained after screening on Sieve No. 015 and determined by us in [6] as Sspec1 for Sample B1 and Sample B2. In particular, it was $S_{\text {specl }}=240 \mathrm{~m}^{2} / \mathrm{kg}$ for Sample B1, and $S_{\text {spec }}=260 \mathrm{~m}^{2} / \mathrm{kg}$ for Sample B2. Therefore, $G I=3.0 \mathrm{~m}^{2} \bullet \mathrm{kg}^{-1} \cdot \mathrm{min}^{-1}$ for light concrete (B2), and $G I=6.7 \mathrm{~m}^{2} \cdot \mathrm{kg}^{-1} \cdot \mathrm{min}^{-1}$ for heavy concrete (B1). The data obtained show that Concrete B1 tested features by grindability more than twice that of Concrete B2. In our opinion, the seemingly contradictory fact noted can be explained using the following hypothetical model: destruction is an irreversible violation of the continuity of the medium under the influence of loads (particle destruction to a size of $0.1 \mu \mathrm{m}$ is called grinding), and it is determined by the material strength properties only at the same loading mechanism. In its turn, the strength of solids is a combination of two factors, namely the resistance to destruction (compressive strength) and irreversible shape change (plastic deformation) under the influence of external loads. The latter factor is dominant in the me-

\section{Table 1}

Specific surface area and particle size properties of powders used

\begin{tabular}{|c|c|c|}
\hline Test sample & Specific surface area $\left(\boldsymbol{S}_{\text {spec }}\right), \mathbf{~ m}^{\mathbf{2}} \mathbf{k g}$ & $\begin{array}{c}\text { Average mass diameter } \\
\text { of particles }(\boldsymbol{d}), \boldsymbol{\mu m}\end{array}$ \\
\hline PC500 & 430 & 4.5 \\
\hline B1 & 440 & 5.9 \\
\hline B2 & 350 & 7.5 \\
\hline
\end{tabular}


Table 2

Binding performance of test samples

\begin{tabular}{|c|c|c|c|c|}
\hline Sample & Contraction, ml/g & Binder activity, MPa & $\begin{array}{c}\text { Bending strength, } \\
\text { MPa }\end{array}$ & $\begin{array}{c}\text { Compressive } \\
\text { strength, MPa }\end{array}$ \\
\hline PC500 & 3.05 & 41.9 & 4.68 & 73.58 \\
\hline B1 & 0.28 & 4.0 & 0.17 & 0.72 \\
\hline B2 & 0.35 & 5.1 & 0.15 & 1.04 \\
\hline PC-10B1 & - & - & 5.12 & 49.31 \\
\hline PC-10B2 & - & - & 4.44 & 57.92 \\
\hline
\end{tabular}

chanical dispersion of solids. Therefore, Concrete Sample B1 has a lower ability to exhibit plastic deformation.

Another important parameter of powder systems that affects their reactivity is the shape of crushed particles determined based on the average diameter calculation according to the expression (2). This approach implemented for the concrete samples tested gave the following results. For Sample B1 and Sample B2 dcalc was $5.8 \mu \mathrm{m}$ and $7.6 \mu \mathrm{m}$ (respectively); at the same time, $\Delta d=\left|d_{\text {calc }}-d_{\text {ex }}\right|$ has the same value equal to $0.1 \mu \mathrm{m}$ for the concrete samples tested. A good coincidence of the calculated and experimental dimensional properties of the particles may indicate that their spherical shape is approximately the same, and, consequently, their reactivity is close as determined by the geometric structure. In contrast, the calculation of the dcalc value for PC500 used showed that this parameter is equal to $5.5 \mu \mathrm{m}$ and $\Delta d=1.0 \mu \mathrm{m}$. It is known that the shape of the cement grain can be changed significantly during the binder production process depending on the grinding unit type $[18,19]$. The difference in the calculated value of the linear size of cement particles and the experimentally determined one may indicate that in our case the particles have a fragmentary "crushed stone" shape with sharp corners and a highly developed configuration. An important conclusion from these experiments may be the following statement. The grinding principle used, which is implemented at the grinding unit used (planetary ball mill), is ineffective for carrying out the process of concrete scrap mechanical grinding in order to obtain a dispersed powder with a highly developed active surface.

Following the studies, the amount of contraction (volumetric deformation of powder systems during hydration) and the forecast of their possible activity when used as binders were determined at the Cement-Prognoz unit (Table 2) for Sample PC500, Sample B1 and Sample B2. In addition, beams made of cement-sand mortar and solutions with cement replaced by the studied powder from Sample B1 and Sample B2 were manufactured and tested for physical and mechanical characteristics (bending strength, compressive strength) to assess the binding capacity. Additionally, strength test samples were made with $10 \%$ of cement replaced by $\mathrm{B} 1$ and $\mathrm{B} 2$ highly dispersed concrete scrap powders (PC-10B1 and PC-10B2, respectively). The values of the obtained properties are presented in Table 2.

The obtained data showed that M500 cement contraction and activity, as expected, have sufficient values characteristic of hydration-type curing binders. For powders prepared from concrete scrap, the effect of hydration is also noted but its value is an order of magnitude lower in quantitative terms. This explains the near-zero strength properties of beams based on waste concrete mineral powders. At the same time, B1 and B2 highly dispersed system additives introduced into Portland cement can allow controlling the shrinkage process during the concrete production or operation processes to avoid the occurrence of spontaneous stresses in the material and, as a result, microcracking with potentially deteriorated physical and mechanical properties of construction products. Thus, it is found that waste concrete powders of this dispersion degree (specific surface area) can be used as highly dispersed fillers.

Composite binder (CB) based on Portland cement (90\%) and highly dispersed waste concrete powder (10\%) features by a $21 \%$ decrease in compressive strength compared to Portland cement for a composite with the light concrete powder additive and a $33 \%$ decrease in strength for $\mathrm{CB}$ with the heavy concrete powder additive. However, $\mathrm{CB}$ deformation properties virtually do not change (when adding Concrete Powder B2, bending strength reduced by $5 \%$ relative to PC500; when adding Concrete Powder B1, bending strength increased by $9 \%$ ). Thus, it can be concluded that the highly dispersed powder of light concrete added as a component of $\mathrm{CB}$ makes it possible to obtain a concrete composite of a higher strength class compared to $\mathrm{CB}$ with a highly dispersed additive of heavy concrete, while reducing the cement consumption.

We made concrete samples in the form of cubes with crushed stone $(5 \mathrm{~mm})$ from light and heavy concrete used as an aggregate with the same cement content and equal water-cement and water-solid ratio. After 28 days of holding under normal curing conditions, samples were tested for compressive strength. The test results showed that 
the compressive strength of concrete with crushed stone from waste light and heavy concrete was $15.45 \mathrm{MPa}$ and 43.48 MPa, respectively. Therefore, it can be concluded that the higher the residual strength class of concrete scrap used as a coarse aggregate in the concrete production process, the higher the compressive strength values of the final product.

\section{CONCLUSIONS}

The following provisions can be noted as the main results of the research conducted.

1. As the main integral criteria for choosing the rational use of waste concrete produced when demolishing buildings and structures after their long-term operation, it is advisable to use the value of the residual compressive strength, the grindability of raw materials and the contraction of powders obtained from concrete scrap.

2. It is rational to use powders from the waste concrete fraction with low residual strength properties and grindability obtained by mechanical grinding to a specific surface area comparable to that of Portland cement used and having a higher value of contraction as a component of a composite binder.

3. Concrete scrap fractions featuring by increased grindability and residual strength properties are optimally used for the preparation of crushed stone aggregate in the concrete composite production process.

\section{REFERENCES}

1. Fayzrakhmanov I.I., Khaliullin M.I., Leklu A.N., Amiri O. Use of finely dispersed screenings of concrete scrap in cement compositions to obtain mortars. News of the Kazan State University of Architecture and Engineering. 2016; 4 (38): 395-401.

2. Larsen O.A., Narut V.V., Voronin V.V. Recycling technology of concrete scrap in order to obtain self-compacting concrete. Building and reconstruction. 2020; 2 (88): 61-66.

3. Gusev B.V., Kudryavtseva V.D., Potapova V.A. Concretes with nano-additive from fired reclaimed concrete. Nanotechnologies in Construction. 2020; 12 (5): 245-249. DOI: 10.15828/2075-8545-2020-12-5-245-249.

4. Krasinikova N.M., Khozin V.G. Recycling of concrete scrap as raw materials for cement concrete. Construction Materials. 2020; 1(2): 56-65. DOI: 10.31659/0585-430X-2020-778-1-2-56-65.

5. Gusev B.V., Krivoborodov Yu.R., Potapova V.A. Possibility of secondary use of concrete breaker. Tekhnika $i$ tekhnologiya silikatov. 2020; 27(1): 28-31.

6. Ayzenshtadt A.M., Drozdyuk T.A., Danilov V.E., Frolova M.A., Garamov G.A. Surface activity of concrete waste powders. Nanotechnologies in Construction. 2021; 13(2): 108-116. Available from: doi: 10.15828/2075-85452021-13-2-108-116.

7. Lesovik R.V., Ahmed A.A.A., Al Mamouri S.K.S., Gunchenko T.S. Composite binders based on concretes crap. Bulletin of BSTU named after V.G.Shukhov. 2020; 7: 8-18. DOI: 10.34031/2071-7318-2020-5-7-8-18.

8. Lesovik R.V., Akhmed A.A.A., Alaskhanov A.Kh. Binder from the dusty fraction of fragments of destroyed buildings and structures in Iraq. Regional Architecture and Engineering. 2020; 1(42): 69-76.

9. Adamtsevich A.O., Pashkevich S.A., Pustovgar A.P. Using calorimetry to predict the strength growth of accelerated hardening cement systems. Magazine of Civil Engineering. 2013; 3: 36-42.

10. Drozdyuk T.A., Ayzenshtadt A.M., Frolova M.A., Nosulya A. A. Assessment of the activity of a mineral binder based on saponite-containing material. The Construction Materials. 2016; 9: 76-79.

11. Usherov-Marshak A.V. Calorimetry of cement and concrete. Kharkov: Fakt. 2002.

12. Serdyukova A.A., Rakhimbaev I.Sh. Influence of water-cement ratio on the kinetics of heat release of cements. The Journal Cement and its Applications. 2012; 3: 123-124.

13. Gazizov Kh.V. Influence of expanding additives on the contraction of oil well cements. Inzhenernaya praktika. 2012; 11: 72-75.

14. Beley I.I. Methods for compensating for contraction during hardening of Portland cement mortars. Bulatovskiye chteniya (sbornik statey). 2018; 43-49.

15. Krasinikova N.M., Khozin E.V., Khozin V.G., Morozova N.M. Research of grindability of dry mixes for foam concrete. Kazan Technological University Bulletin. 2015; 18(8): 187-190.

16. Mishchenko Lidiya, Hatton Benjamin, Bahadur Vaibhav, Taylor J. Ashley, Krupenkin Tom, Aizenberg Joanna. Design of Ice-free Nanostructured Surfaces Based on Repulsion of Impacting Water Droplets. Nanoletters. 2010; 4 (12): 7699-7707. 
17. Danilov V.E., Ayzenstadt A.M. Comprehensive approach to the assessment of nanosized fractions of polydisperse systems of crushed rocks. Nanotechnologies in Construction. 2016; 8(3): 97-110. DOI: 10.15828/2075-85452016-8-3-97-110.

18. Zlobin I.A., Mandrikova O.S., Borisov I.N. Influence of the method of mechanical action on the geometric shape and nature of the surface of cement particles. The Journal Cement and its Applications. 2015; 5: 56-60.

19. He Huan, Stroeven Piet, Pirard Eric, Courard Luc. On the Shape Simulation of Aggregate and Cement Particles in a DEM System". Advances in Materials Science and Engineering. 2015; 2015: 692768. DOI: 10.1155/2015/692768.

\section{INFORMATION ABOUT THE AUTHORS}

Arkady M. Ayzenshtadt - Dr. Sci. (Chem.), Professor, Head of the Department of Composite Materials and Environmental Engineering, the Honored Worker of Higher Education of the Russian Federation, the Honored Worker of Science and High Technologies of the Russian Federation, Northern (Arctic) Federal University named after M.V. Lomonosov, Arkhangelsk, Russia, a.isenshtadt@narfu.ru, https://orcid.org/0000-0003-2904-2549

Victor E. Danilov - Cand. Sci. (Eng.), Associate Professor of the Department of Composite Materials and Environmental Engineering, Northern (Arctic) Federal University named after M.V. Lomonosov, Arkhangelsk, Russia, v.danilov@narfu.ru, https://orcid.org/00000002-5013-5339

Tatiana A. Drozdyuk - Senior Lecturer of the Department of Composite Materials and Environmental Engineering, Northern (Arctic) Federal University named after M.V. Lomonosov, Arkhangelsk, Russia, t.drozdyuk@narfu.ru, https://orcid.org/0000-0003-1847-408X

Maria A. Frolova - Cand. Sci. (Chem.), Associate Professor of the Department of Composite Materials and Environmental Engineering, Northern (Arctic) Federal University named after M.V. Lomonosov, Arkhangelsk, Russia, m.aizenstadt@narfu.ru, https://orcid. org/0000-0003-4079-5066

Georgiy A. Garamov - Master Student, Northern (Arctic) Federal University named after M.V. Lomonosov, Arkhangelsk, Russia, georgiigaramov1997@gmail.com, https://orcid.org/0000-0002-5496-1080

\section{CONTRIBUTION OF THE AUTHORS}

Arkady M. Ayzenshtadt - scientific management; research concept; methodology development; scientific text editing; final conclusions.

Victor E. Danilov - research concept; methodology development; experimental work; experimental data processing; collection of material; writing the draft; final conclusions.

Tatiana A. Drozdyuk - experimental work; experimental data processing; writing the draft; work with the editorial staff of the journal.

Maria A. Frolova - research concept, writing the draft; final conclusions.

Georgiy A. Garamov - experimental work; experimental data processing; collection of material.

\section{The authors declare no conflicts of interests.}

The article was submitted 05.09.2021; approved after reviewing 28.09.2021; accepted for publication 01.10.2021. 